\title{
PENDIDIKAN KESEHATAN TENTANG BANTUAN HIDUP DASAR DENGAN METODE SIMULASI TERHADAP KETERAMPILAN MAHASISWA
}

\author{
Apriani $^{1}$, Abdul Syafei ${ }^{2}$ \\ ${ }^{1,2}$ Program Studi Ilmu Keperawatan STIK Siti Khadijah Palembang \\ Jalan Demang Lebar Daun Lorok Pakjo Palembang 30117 \\ Email : apriani@stik-sitikhadijah.ac.id
}

\begin{abstract}
Abstrak
Kondisi kegawatdaruratan dapat terjadi di mana saja, kapan saja dan sudah menjadi tugas dari petugas kesehatan untuk menangani masalah tersebut. Serangan jantung mendadak menjadi penyebab utama kematian di luar rumah sakit dan di rumah sakit. Kematian terjadi biasanya karena ketidakmampuan petugas kesehatan untuk menangani penderita pada fase gawat darurat (Golden Period). Ketika pasien segera menerima Bantuan Hidup Dasar, pasien tersebut memiliki kesempatan hidup yang lebih mungkin terjadi. Penelitian ini bertujuan untuk mengetahui pengaruh pendidikan kesehatan tentang Bantuan Hidup Dasar dengan metode simulasi terhadap keterampilan mahasiswa STIK Siti Khadijah Palembang. Desain penelitian ini menggunakan pre eksperiment dengan pendekatan one group pre-test and post-test design. Penelitian ini dilakukan pada tanggal 11 - 16 November 2019. Sampel pada penelitian ini berjumlah 68 responden dengan tehnik pengambilan sampel purposive sampling. Instrumen yang digunakan yaitu lembar checklist dari American Heart Association tahun 2015. Hasil penelitian menunjukkan bahwa ada pengaruh pendidikan kesehatan tentang Bantuan Hidup Dasar dengan metode simulasi terhadap keterampilan mahasiswa dengan $p$ value $=0.000$. Diharapkan mahasiswa mampu mengaplikasikan pertolongan pertama pada pasien dengan henti nafas dan henti jantung dengan tindakan Bantuan Hidup Dasar ketika menemukan korban dalam kondisitersebut.
\end{abstract}

\section{Kata kunci : Pendidikan Kesehatan, Bantuan Hidup Dasar, Keterampilan}

\begin{abstract}
Emergency conditions can occur anywhere, anytime and it is the duty of health workers to deal with these problems. Sudden heart attack is the leading cause of death outside of hospitals and in hospital. Deaths occur usually due to the inability of health workers to treat sufferers in the emergency phase (Golden Period). When the patient immediately receives Basic Life Support, that patient has a more likely chance of life. This study aims to determine the effect of health education on Basic Life Support with the simulation method on skills of college students STIK Siti Khadijah Palembang. Design of this study used pre-experiment with one group pre-test and post-test design approaches. This research was conducted on 11-16 November 2019. The sample in this study amounted to 68 respondents with a purposive sampling technique. The instrument that used was a checklist sheet from American Heart Association 2015. The results showed that there was an effect of health education on Basic Life Support with simulation methods on skills of college students with $p$ value $=0.000$. It is hoped that college students will be able to apply first aid to patients with stopping breathing and cardiac arrest by Basic Life Support when they find a victim in that condition.
\end{abstract}

Keywords : Health Education, Basic Life Support, Skills 


\section{PENDAHULUAN}

Kondisi kegawatdaruratan dapat terjadi di mana saja, kapan saja dan sudah menjadi tugas dari petugas kesehatan untuk menangani masalah tersebut. Walaupun begitu, tidak menutup kemungkinan kondisi kegawatdaruratan dapat terjadi pada daerah yang sulit untuk membantu korban sebelum ditemukan oleh petugas kesehatan menjadi sangat penting (Sudiharto \& Sartono, 2011). Salah satu kondisi kegawatdaruratan yang sering terjadi adalah serangan jantung.

Serangan jantung mendadak menjadi penyebab utama kematian di luar rumah sakit dan di rumah sakit. Penelitian di Amerika Serikat menunjukkan sebanyak $70 \%$ serangan jantung di luar rumah sakit atau out-ofhospital cardiac arrests (OHCAs) terjadi di rumah, dan sekitar 50\% tidak disaksikan. Hasil dari OHCA buruk, hanya 10,8\% korban dewasa dengan serangan jantung nontraumatik yang telah menerima upaya resusitasi dari emergency medical service (EMS) atau layanan darurat medis mampu bertahan hidup sampai rumah sakit. Serangan jantung di rumah sakit atau in hospital cardiac arrest (IHCA) memiliki hasil yang lebih baik, dengan $22,3 \%$ sampai $25,5 \%$ orang dewasa yang masih mampu bertahan hidup (AHA, 2015).

Menurut Nugroho (2017), ketika pasien segera menerima Bantuan Hidup Dasar (BHD), pasien tersebut memiliki kesempatan hidup yang lebih mungkin terjadi, oleh karena itu menghubungi Emergency Call adalah langkah awal yang harus dilakukan oleh penolong, kemudian penolong segera melakukan Resusitasi Jantung Paru (RJP) untuk membantu pasien agar tetap bertahan hidup. Hal tersebut sesuai dengan data American Heart Association (2015) sebesar $40,1 \%$ korban respiratory arrest (henti nafas) dan cardiac arrest (henti jantung) yang terselamatkan setelah dilakukan RJP.

Kematian terjadi biasanya karena ketidakmampuan petugas kesehatan untuk menangani penderita pada fase gawat darurat (Golden Period). Ketidakmampuan tersebut bisa disebabkan oleh tingkat keparahan, kurang memadainya peralatan, belum adanya system yang terpadu dan pengetahuan dalam penanggulangan gawat darurat yang masih kurang (Sudiharto \& Sartono, 2011).

Sistem Pelayanan Gawat Darurat Terpadu (SPGDT) menjadi solusi terpilih terbaik untuk memberi bantuan bagi seseorang dengan kriteria "gawat darurat". Keberhasilan pertolongan terhadap penderita gawat darurat itu tergantung kepada tiga hal yaitu kecepatan ditemukannya penderita,, kecepatan meminta bantuan pertolongan serta kecepatan dan ketepatan bantuan yang diberikan dan dilakukan oleh orang yang kompeten. Kondisi penderita yang membutuhkan jalan napas yang bersih, ventilasi paru adekuat, sirkulasi darah yang baik dan terhindar dari perdarahan lanjut serta terlindungi dari kecacatan menjadi poin penting bahwa seorang penolong pertama harus mempunyai dasar keilmuan yang memadai (Pusponegoro, 2010).

Pada sebagian besar kasus, dari awal kejadian pasien terkena henti jantung dan henti napas sampai tiba di layanan kegawatdaruratan membutuhkan waktu yang cukup lama. Selain jarak tempuh, prognosis pasien juga dipengaruhi oleh tatalaksana awal resusitasi jantung paru. Hingga saat ini, hanya sebagian kecil dari pasien henti jantung yang menerima resusitasi jantung paru (RJP) dari masyarakat yang menyaksikan di tempat kejadian, hal ini disinyalir akibat kurangnya pengetahuan masyarakat terkait tindakan RJP yang harusnya dilakukan kepada pasien di tempat kejadian (Wissenberg, M. et al., 2013)

Pendidikan kesehatan dengan metode simulasi merupakan salah satu metode untuk memberikan pengetahuan, pengalaman dan keterampilan kepada mahasiswa tentang Bantuan Hidup Dasar. Menurut Notoatmodjo (2010), keunggulan dari metode simulasi ini adalah perhatian responden dapat dipusatkan kepada hal-hal yang dianggap penting oleh pendidik dan mencoba mempraktikkan secara langsung proses pendidikan yang telah diberikan 
sehingga hal yang penting itu dapat diamati secara teliti. Basic life support atau bantuan hidup dasar harus diberikan pada korbankorban yang mengalami henti napas, henti jantung, dan perdarahan. Keterampilan basic life support dapat diajarkan kepada siapa saja. Setiap orang dewasa seharusnya memiliki keterampilan basic life support (Frame, 2010).

Keterampilan melakukan resusitasi jantung paru (RJP) harus dimiliki setiap orang untuk mengurangi dampak buruk atau keparahan gejala sisa pasien henti jantung. Keterampilan dalam tindakan pertolongan awal ini bertujuan untuk oksigenasi darurat, mempertahankan fungsi jantung paru melalui ventilasi dan sirkulasi buatan. Dengan demikian nantinya diharapkan ventilasi dan sirkulasi dapat pulih spontan sehingga mampu melakukan oksigenasi secara mandiri. Hal ini akan memberikan prognosis yang lebih baik pada pasien, menurunkan angka morbiditas dan mortalitas pasien. Kemampuan untuk melakukan CPR lebih didasarkan pada kekuatan tubuh daripada usia (Sukiman, 2012).

Berdasarkan hasil penelitian yang dilakukan oleh Hidayat, et al., (2015), didapatkan nilai rata-rata keterampilan responden sebelum pendidikan kesehatan adalah 1,50 setelah diberikan pendidikan kesehatan menjadi 3,21. Begitu juga dengan penelitian yang dilakukan oleh Fatmawati, et al., (2019) didapatkan nilai rata-rata keterampilan responden sebelum pelatihan sebesar 2,83 $\pm 0,950$ dan sesudah pelatihan

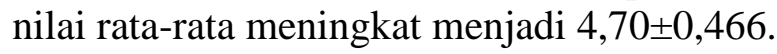

Program Studi Ilmu Keperawatan STIK Siti Khadijah Palembang terletak di Jl. Demang Lebar Daun Palembang, memiliki mini hospital dan ruangan gawat darurat yang didesain sesuai keadaan kegawatdaruratan dan fasilitas yang lengkap dengan alat-alat kegawatdaruratan serta pernah mengadakan pelatihan Basic Trauma \& Cardiac Life Support (BTCLS) yang mendatangkan pelatih atau instruktur dari Jakarta.

Mahasiswa merupakan bagian dari masyarakat, dimana turut bertanggung jawab terhadap permasalahan ini, sehingga pendidikan kesehatan tentang Bantuan Hidup
Dasar ini merupakan keterampilan yang harus diketahui dan dikuasai oleh mahasiswa keperawatan. Mahasiswa Program Studi Ilmu Keperawatan tahun 2019 berjumlah 171 orang, yang terdiri dari kelas Reguler dan Kelas Alih Program. Mahasiswa yang sedang dalam proses pembelajaran Keperawatan Gawat Darurat adalah mahasiswa semester 7 yang berjumlah 68 orang. Berdasarkan uraian diatas, maka penulis tertarik untuk meneliti tentang Pengaruh Pendidikan Kesehatan tentang Bantuan Hidup Dasar (BHD) dengan Metode Simulasi terhadap Keterampilan Mahasiswa di STIK Siti Khadijah Palembang.

\section{METODE PENELITIAN Desain Penelitian}

Jenis penelitian ini adalah penelitian kuantitatif. Desain penelitian ini menggunakan pre eksperiment dengan pendekatan one group pre-test and post-test design.

\section{Waktu dan Tempat Penelitian}

Penelitian telah dilakukan pada tanggal 11 - 16 November 2019 bertempat di STIK siti Khadijah Palembang

\section{Prosedur}

Penelitian ini dilakukan setelah mendapatkan perizinan dari STIK Siti Khadijah Palembang selaku tempat penelitian dan persetujuan dari responden. Pendidikan kesehatan tentang Bantuan Hidup Dasar (BHD) diberikan sebanyak 1 kali dengan metode simulasi yang memuat pesan tentang pengertian, tujuan, indikasi, dan langkah-langkah dalam Bantuan Hidup Dasar. Sebelum diberikan pendidikan kesehatan, terlebih dahulu diukur keterampilan mahasiswa dengan menggunakan lembar checklist Bantuan Hidup Dasar dari American Heart Association tahun 2015. Selanjutnya setelah diberikan pendidikan kesehatan, keterampilan mahasiswa diukur kembali dengan menggunakan lembar checklist yang 
sama. Setelah didapatkan data skor keterampilan maka selanjutnya diolah dan dianalisis dengan menggunkan program komputer.

\section{Target/ Subjek Penelitian}

Populasi dalam penelitian ini adalah seluruh mahasiswa/i semester VII Program Studi Ilmu Keperawatan STIK Siti Khadijah Palembang Tahun 2019 sebanyak 68 mahasiswa. Sampel dalam penelitian ini diambil dengan tehnik purposive sampling. Jumlah sampel setelah dipilih berdasarkan kriteria inklusi dan ekslusi yaitu sebanyak 68 sampel.

\section{Data, Instrumen, dan Teknik Pengumpulan Data}

Penelitian ini menggunakan data primer yang dikumpulkan dengan cara menggunakan lembar checklist Bantuan Hidup Dasar dari American Heart Association tahun 2015. Terdiri dari 14 aspek keterampilan yang dinilai dan 1 penilaian aspek profesional.

\section{Teknik Analisis Data}

Analisa data pada penelitian terbagi menjadi 2 yaitu analisa univariat untuk mendapatkan distribusi frekuensi dari masing- masing variabel dan analisa bivariat dengan menggunakan uji Wilcoxon untuk mengetahui adanya pengaruh pendidikan kesehatan tentang Bantuan Hidup Dasar dengan metode simulasi terhadap keterampilan mahasiswa.

\section{HASIL PENELITIAN DAN PEMBAHASAN}

Tabel 1

Skor Keterampilan Mahasiswa Sebelum Diberikan Pendidikan Kesehatan tentang BHD dengan Metode Simulasi $(n=68)$

\begin{tabular}{lllll}
\hline Variabel & Mean & Median & Std.Dev & $\begin{array}{l}\text { Min- } \\
\text { Max }\end{array}$ \\
\hline $\begin{array}{l}\text { Skor } \\
\text { keterampilan } \\
\text { sebelum }\end{array}$ & 69,47 & 70 & 7,008 & $55-$ \\
& & & & 80 \\
\hline
\end{tabular}

Tabel 1 didapatkan nilai rerata skor sebelum diberikan pendidikan kesehatan tentang BHD yaitu 69.47 dengan standar deviasi 7.008, median 70, skor paling rendah adalah 55, sedangkan untuk skor paling tinggi adalah 80 .

Tabel 2

Skor Keterampilan Mahasiswa Sesudah Diberikan Pendidikan Kesehatan tentang BHD dengan Metode Simulasi $(n=68)$

\begin{tabular}{lllll}
\hline Variabel & Mean & Median & Std.Dev & $\begin{array}{l}\text { Min- } \\
\text { Max }\end{array}$ \\
\hline $\begin{array}{l}\text { Skor } \\
\text { keterampilan } \\
\text { sesudah }\end{array}$ & 76,41 & 77 & 6,414 & $64-86$ \\
\hline
\end{tabular}

Tabel 2 didapatkan nilai rerata skor keterampilan sesudah diberikan pendidikan kesehatan tentang BHD yaitu 76.41 dengan standar deviasi 6.414 , median 77 , skor paling rendah adalah 64 , sedangkan untuk skor paling tinggi adalah 86 .

\section{Analisa Bivariat}

1. Pengaruh Pendidikan Kesehatan tentang Bantuan Hidup Dasar (BHD) dengan Metode Simulasi terhadap Keterampilan Mahasiswa

Pengaruh pendidikan kesehatan tentang Bantuan Hidup Dasar terhadap keterampilan mahasiswa dianalisis dengan menggunakan uji Wilcoxon dikarenakan data tidak terdistribusi secara normal. 
Tabel 3.

Pengaruh Pendidikan Kesehatan

Tentang Bantuan Hidup Dasar

(BHD) dengan Metode Simulasi terhadap Keterampilan Mahasiswa

\begin{tabular}{llcc}
\hline \multicolumn{1}{c}{ Variabel } & Median & $\begin{array}{c}\text { Min- } \\
\text { Mix }\end{array}$ & $\begin{array}{c}P- \\
\text { Value }\end{array}$ \\
\hline $\begin{array}{l}\text { Skor keterampilan } \\
\text { sebelum }\end{array}$ & 70 & $\mathbf{5 5 - 8 0}$ & $\mathbf{0 , 0 0 0}$ \\
\hline $\begin{array}{l}\text { Skor keterampilan } \\
\text { sesudah }\end{array}$ & 77 & $\mathbf{6 4 - 8 6}$ & \\
\hline
\end{tabular}

Berdasarkan tabel 3 menunjukkan bahwa median skor keterampilan sebelum diberikan pendidikan kesehatan tentang Bantuan Hidup Dasar (BHD) yaitu 70, dengan skor paling rendah adalah 55, skor paling tinggi adalah 80, sedangkan median skor keterampilan sesudah diberikan pendidikan kesehatan tentang Bantuan Hidup Dasar (BHD) yaitu 77, skor paling rendah adalah 64, skor paling tinggi adalah 86 .

Hasil uji wilcoxon didapatkan $\mathrm{p}$ value $=$ 0.000, maka dapat disimpulkan bahwa ada pengaruh pendidikan kesehatan tentang Bantuan Hidup Dasar (BHD) dengan metode simulasi terhadap keterampilan mahasiswa STIK Siti Khadijah Palembang.

Hasil penelitian ini sejalan dengan hasil penelitian yang dilakukan oleh Fatmawati, et. al., (2019) yang menyatakan bahwa ada peningkatan keterampilan Mahasiswa Program Studi Ilmu Keperawatan Jenjang D.III Stikes Yarsi Mataram Tahun 2018 dari 2,83 menjadi 4,70 point (peningkatan sebesar 1,47 point). Begitu pula dengan hasil penelitian yang dilakukan oleh Turambi (2016) yang menyatakan ada pengaruh pelatihan bantuan hidup dasar terhadap peningkatan keterampilan siswa dengan nilai $\mathrm{p}=0,000<0.05$. Hal ini menunjukkan bahwa pelatihan bantuan hidup dasar memberi hasil yang bermakna.

Menurut Young dalam Ningsih (2011) menjelaskan bahwa presentase peningkatan kemampuan seseorang $90 \%$ didapatkan dari melihat langsung, mempraktikkan serta memperagakan pengetahuan dan keterampilan yang diajarkan.

Pendidikan kesehatan dengan metode simulasi merupakan salah satu metode untuk memberikan pengetahuan, pengalaman dan keterampilan kepada mahasiswa. Menurut Notoatmodjo (2010), keunggulan dari metode simulasi ini adalah perhatian responden dapat dipusatkan kepada hal-hal yang dianggap penting oleh pendidik dan mencoba mempraktikkan secara langsung proses pendidikan yang telah diberikan sehingga hal yang penting itu dapat diamati secara teliti.

Bantuan Hidup Dasar atau Basic Life Support merupakan sekumpulan intervensi yang bertujuan untuk mengembalikan dan mempertahankan fungsi vital organ pada korban henti jantung dan henti nafas. Intervensi ini terdiri dari pemberian kompresi dada dan bantuan nafas (Hadisman, 2014). Bantuan Hidup Dasar dilakukan sampai bantuan atau pertolongan lanjutan datang. Bantuan hidup dasar merupakan bagian dari pengelolaan gawat darurat medik yang bertujuan untuk mencegah berhentinya sirkulasi atau berhentinya respirasi (Frame, 2010). Mahasiswa harus memiliki keterampilan yang profesional, keterampilan (kompetensi) khusus tersebut bisa didapatkan melalui pendidikan dan pelatihan tentang kegawatdaruratan. Keterampilan tersebut harus selalu ditingkatkan atau dikembangkan dan dipelihara sehingga menjamin perawat dapat melaksanakan peran dan fungsinya secara professional (Bertnus, 2009 dalam Fatmawati, 2019)

Frame (2010) menyatakan bahwa Bantuan Hidup Dasar (BHD) dapat diajarkan kepada siapa saja. Setiap orang dewasa seharusnya memiliki keterampilan BHD, bahkan anak-anak juga dapat diajarkan sesuai dengan kapasitasnya, agar dapat memberikan pertolongan keselamatan dengan segera. Menurut Thygerson (2009) keterlambatan hanya beberapa menit jantung seseorang berhenti, dapat memberi perbedaan antara hidup dan mati, dan memberi bantuan sementara sampai mendapatkan perawatan medis yang 
kompeten.

Berdasarkan hasil penelitian dan penjelasan teori di atas, maka peneliti berasumsi bahwa pemberian pendidikan kesehatan tentang Bantuan Hidup Dasar (BHD) dengan metode simulasi dapat meningkatkan keterampilan mahasiswa keperawatan dalam melakukan pertolongan pertama pada siapapun dalam keadaan yang gawat darurat terutama pada orang yang mengalami henti jantung dan henti nafas yang merupakan indikasi dari pemberian BHD. Semakin sering mahasiswa terpapar dengan pendidikan kesehatan tentang Bantuan Hidup Dasar (BHD) yang diberikan melalui simulasi, semakin baik atau tinggi tingkat keterampilan mahasiswa dalam melakukan pertolongan pertama kegawatdaruratan BHD pada pasien yang henti jantung dan henti nafas.

\section{KESIMPULAN}

Berdasarkan hasil penelitian dan pembahasan di atas, maka diperoleh kesimpulan sebagai berikut:

1. Rerata skor keterampilan sebelum diberikan pendidikan kesehatan tentang Bantuan Hidup Dasar (BHD) dengan metode simulasi sebesar 69.47

2. Rerata skor keterampilan sesudah diberikan pendidikan kesehatan tentang Bantuan Hidup Dasar (BHD) dengan metode simulasi sebesar 76.41

3. Ada pengaruh pendidikan kesehatan tentang Bantuan Hidup Dasar (BHD) dengan metode simulasi terhadap keterampilan mahasiswa STIK Siti Khadijah Palembang dengan $\mathrm{p}$ value $=$ 0.000

\section{SARAN}

Berdasarkan hasil penelitian, diharapkan mahasiswa mampu mengaplikasikan pertolongan pertama pada pasien dengan henti nafas dan henti jantung dengan melakukan tindakan Bantuan Hidup Dasar (BHD) ketika menemukan korban dalam kondisi tersebut. Untuk peneliti selanjutnya, dapat melakukan penelitian lebih lanjut dengan menggunakan metode dan media penelitian yang lain, serta dengan instrumen penelitian lainnya seperti kuesioner atau wawancara.

\section{UCAPAN TERIMA KASIH}

Penulis mengucapkan terima kasih kepada semua pihak yang telah membantu dan mendukung terlaksananya penelitian ini.

\section{DAFTAR PUSTAKA}

American Heart Association. 2015. Highlights of the 2015 American Heart Association Guidelines Update for CPR and ECC.

Fatmawati, et al., 2019. Efektifitas Edukasi Basic Life Support Dengan Media Audiovisual dan Praktik Terhadap peningkatan Pengetahuan dan Keterampilan Mahasiswa Program Studi Ilmu Keperawatan Jenjang D.III Stikes Yarsi Mataram Tahun 2018. Jurnal Kesehatan Qamarul Huda ,Volume 7, Nomor 1 Juni 2019

Fauziah, DKK. (2017). Penggunaan Leaflet terhadap Peningkatan

Pengetahuan tentang Pemeriksaan Payudara Sendiri. GASTER : 15(2). Hal. 204-

213.

Frame. (2010). PHTLS: Basic and Advanced Prehospital Trauma Life Support. Jakarta: EGC.

Hadisman. (2014). Gawat Darurat Medis Praktik. Yogyakarta: Gosyen Publishing

Hidayat, Aris Wahyu, 2015. Pengaruh Pendidikan Kesehatan Terhadap Tingkat Pengetahuan, Sikap Dan Keterampilan Remaja Tentang Bantuan Hidup Dasar (Bhd). Bachelor Thesis, Universitas Muhammadiyah Purwokerto. 
Notoatmodjo, 2010. Metode

Penelitian Kesehatan.

Jakarta. Rineka Cipta

Nugroho, Tamara \& Kirana, 2016. Teori Asuhan Keperawatan Gawat Darurat. Yogyakarta : Nuha Medika

Pusponegoro, A. D. 2010. Basic Trauma Life Support \& Basic Cardiac Life Support. Jakarta : YAGD 118.

Sudiharto \& Sartono. 2011. Basic Trauma Cardiac Life Support. Jakarta: CV. Sagung Seto
Sukiman, 2012.

Pengembangan Media

Pembelajaran.

Yogyakarta: Pustaka

Insan Madani

Turambi, 2016. Pengaruh Pelatihan Bantuan Hidup Dasar (BHD) Terhadap Peni

ngkatan Pengetahuan dan Keterampilan Siswa kelas XI Dan XII SMA Negeri 2 Langowan.

Wissenberg, M. et al., 2013. Association of national initiatives to improve cardiac arrest management with rates of bystander intervention and patient survival after out-ofhospital cardiac arrest. Jama, 310 (13), pp. 1377-84. Available at: http://www.ncbi.nlm.nih.go v/pubm ed 
